\title{
PARQUES ESPORTIVOS COMO ESPAÇO OU LUGAR DE INCLUSÃO OU EXCLUSÃO DE PESSOAS COM DEFICIÊNCIA FÍSICA E VISUAL
}

Recebido em: 02/06/2017

Aceito em: 17/01/2018

\author{
Junior Vagner Pereira da Silval \\ Dirceu Santos Silva ${ }^{2}$ \\ Universidade Federal de Mato Grosso do Sul \\ Campo Grande - MS - Brasil \\ Tânia Mara Vieira Sampaio \\ Instituto Federal de Goiás - Campus Luziânia \\ Luziânia - GO - Brasil
}

RESUMO: O objetivo é analisar se os parques esportivos de Campo Grande/MS se constituem como espaço e/ou lugar de inclusão ou exclusão de pessoas com deficiência física e visual. Trata-se de uma pesquisa descritiva/exploratória, com ênfase na avaliação morfológica normativa dos seguintes itens dos parques esportivos: estacionamento, passeio público, acesso, circulação horizontal, circulação vertical, sanitários e vestiários, mobiliários, e espaços e equipamentos. Verificou-se que, com exceção de dois estacionamentos do Parque das Nações Indígenas, e as vias de circulação horizontal dos Parques Jaques da Luz, Ayrton Senna, Ecológico do Sóter e Tarsila do Amaral, todos os demais itens analisados est às pessoas com deficiência física e visual. Dessa forma, é possível afirmar que a legislação não tem sido cumprida pelo poder público e os parques esportivos não tem se configurado como lugar de inclusão.

PALAVRAS CHAVE: Atividades de Lazer. Planejamento de Cidades. Área Urbana. Pessoas com Deficiência.

\section{SPORTIVE PARKS AS A SPACE OR PLACE OF INCLUSION OR EXCLUSION OF PEOPLE WITH PHYSICAL AND VISUAL DEFICIENCY}

ABSTRACT: The aim is to analyse the sports park of Campo Grande/MS if they constitute as a space and/or place of inclusion or exclusion of people with physical and visual disability. It is a descriptive/exploratory research, with emphasis on the normative morphological assessment of the following items of the sports parks: parking, public footpath, access, horizontal movement, vertical movement, toilets and changing rooms, furniture and sporting spaces. It was confirmed that, with the exception of two parking lots of the Park of the Indigenous Nations, and the horizontal movement ways

\footnotetext{
${ }^{1}$ Doutor em Educação Física pela Universidade Católica de Brasília, professor adjunto no curso de

${ }^{2}$ Doutor em Educação Física pela Unicamp, atualmente pertence a REDE CEDES MS.
} 
of the Parks Jaques da Luz, Ayrton Senna, Sóter Ecological and Tarsila do Amaral, all other items analyzed are inaccessible to people with physical and visual disabilities.

In this way, it was possible to conclude that the government has not complied with the legislation and the sports parks is not considered for inclusion spaces

KEYWORDS: Leisure Activities. City Planning. Urban Area. Disabled Persons.

\section{Introdução}

Apesar da crescente busca de contato e de reaproximação com a natureza, a cidade ainda se constitui como palco principal das experiências de lazer. A cidade se configura como o cenário cotidiano, que promove a arte do encontre entre os diferentes públicos e faixas etárias (LERNER, 2013).

A cidade consiste em um ambiente físico, composto pela configuração territorial: paisagem, espaço e lugar. A configuração territorial se constitui em um conjunto de formas naturais e artificiais, localizadas num determinado limite de território. Sua constituição é dinâmica, uma vez que aquela configuração territorial que por muito tempo pautou em complexos herdados da natureza, foram manipuladas pelo ser humano. Além disso, a condição foi intensificada com o aperfeiçoamento dos meios de produção, o que corroborou com progressiva substituição dos objetos naturais pelos artificiais (SANTOS, 2009a; SANTOS, 2012).

A paisagem, elemento integrante da configuração territorial, se traduz naquilo que conseguimos alcançar por meio da visão. Assim, corresponde a um fragmento do todo que se materializa na distribuição de formas-objetos naturais e artificiais. Os naturais são aqueles que ainda não sofreram interferência humana e os artificiais são aqueles que já foram transformados (SANTOS, 2012).

A composição da paisagem é fonte da constituição histórica e ocorre por acréscimos, inscritos uns sobre os outros, a fim de que exigências de diferentes 
momentos sejam atendidas. A paisagem só existe por meio de suas formas, que foram criadas em momentos históricos distintos. O espaço, por sua vez, compõe uma função atual, como forma de responder às necessidades atuais da sociedade (SANTOS, 2009a)

A paisagem corresponde a um elemento material, um objeto fixo, que consiste em estruturas físicas, algo que, se não habitada, movimentada e usada pelo ser humano, é obra morta, inanimada. Embora a característica morfológica da estrutura física possa persistir ao longo da história, o mesmo não ocorre com sua significação, pois a função dada a uma paisagem é obra da ação humana (SANTOS, 2009b).

É da necessidade da ação humana sobre as estruturas físicas que uma parceria dialética é criada, o que transforma paisagem em espaço. Assim, o espaço é o movimento sobre a paisagem, trata-se de trabalho vivo (o contexto social) sobre um conjunto de trabalho morto (formas geográficas). É a sociedade encaixada na paisagem: o resultado do encontro entre configuração territorial, paisagem e sociedade (TUAN, 1983; GEHL, 2013).

O espaço se constitui em um conjunto indissociável de sistemas de objetos (fixos) e de sistema de ações (fluxos). Por sistema de objetos/fixos se entende tudo aquilo que existe sobre a superfície da terra, sejam fruto da herança natural ou resultado da ação humana. O sistema de ações/fluxos se constitui como um elemento inerente ao ser humano, à ação sobre a paisagem. $\mathrm{O}$ espaço é a animação dada pelo homem às formas e ao conteúdo, ao valor, a função atribuída à paisagem, pois apenas ele possui objetivo e se pauta em necessidades naturais ou criadas (SANTOS, 2009b).

A partir dessa interpretação é possível encontrar diferentes paisagens que serão transformadas em espaços de lazer, como as artificiais que, embora criadas com fins específicos, em cada momento histórico são usadas para fins diversos. Pode-se destacar 
a casa, o local de trabalho, o comércio e o repouso na sociedade medieval, transformadas na sociedade contemporânea em espaço de descanso. No entanto, devido aos fatores que limitam as possibilidades de lazer no meio urbano, têm sido utilizadas como principal equipamento não-específico de lazer.

Além de proporcionar novas funções e significações às paisagens históricas, pode-se afirmar que cada tipo de sociedade e período histórico criam objetos artificiais específicos de sua época. Podem-se destacar as paisagens artificiais criadas para que as pessoas usufruam o seu tempo disponível, como os parques esportivos, equipamentos caracterizados também como lugares específicos de lazer.

O conceito de lugar, por sua vez, implica em pausa, segurança: é aquilo que inicialmente começou como espaço indiferenciado, mas na medida em que foi melhor conhecido e apropriado passou a serem dotado de identidade, sentimentos, valores e significados para os que dele usufruem (TUAN, 1983). O lugar se constitui por sua existência corpórea e por sua existência relacional (SANTOS, 1997).

A respeito da dialética entre espaço e lugar, Tschoke, Tardivo e Rechia (2011, p. 3) expõem que "o espaço se torna o local da ação humana, onde coexistem as relações entre o ambiente e os sujeitos que nele habitam". Os sujeitos só desenvolvem a noção de pertencimento quando se apropriam do lugar e usufruem a partir de um determinado significado da sua ação.

A transformação de um espaço em lugar está relacionada à sua atratividade, à identificação e ao sentimento de pertencimento que ele provoca nas pessoas, transformado em lugar de permanência e convívio social (JACOBS, 2000).

Espaço e lugar, embora diferentes, são ideias que não podem viver uma sem a outra (TUAN, 1983). É necessário que estratégias sejam criadas a fim de que a cidade 
contemporânea, diferentemente da moderna, seja projetada de forma que proporcione, tanto o deslocamento de pessoas pela cidade, quanto à permanência em lugares de transferência, de encontro e de lazer (GEHL, 2013).

Considerando que, 1) o movimento humano sobre a paisagem origina o espaço; 2) a configuração do espaço em lugar decorre da atratividade e do sentimento de pertencimento que ele promove em todos os seus usuários; 3) para a inclusão de todas as pessoas no parque é necessário pensar em um parque que tenham lugares para crianças, adolescentes e idosos, de forma intergeracional e diferentes públicos que foram excluídos dos lugares historicamente, como o caso das pessoas com deficiências; 4) para que as pessoas com deficiência usufruam de parques esportivos com qualidade, faz-se necessária a eliminação de barreiras, como as arquitetônicas. Dessa forma, a reflexão central da pesquisa envolveu a seguinte questão: os parques esportivos de lazer da cidade de Campo Grande/MS se configuram como espaço e/ou lugar de inclusão ou exclusão de pessoas com deficiência física e visual?

O objetivo do artigo é analisar se os parques esportivos de Campo Grande/MS se constituem em espaço e/ou lugar de inclusão ou exclusão de pessoas com deficiência física e visual.

\section{Material e Método}

O artigo se caracteriza como descritivo/exploratório, pois permite analisar características se os parques esportivos de Campo Grande/MS se configuram como espaço ou lugar para os seus usuários (MARCONI; LAKATOS, 2002). Além disso, a pesquisa presente oportuniza a descoberta de práticas que necessitam ser avaliadas ou 
até mesmo denunciadas, bem como a formulação de alternativas a fim de modificá-las (OLIVEIRA, 2002).

A investigação envolveu todos os parques esportivos de Campo Grande/MS, o que totalizou 5 (Parque das Nações Indígenas, Parque Ecológico do Sóter, Ayrton Senna, Tarsila do Amaral e Jaques da Luz), conforme Quadro 1. O Parque das Nações Indígenas é o principal parque do estado do Mato Grosso do Sul, e dispõe de um Museu do Índio, Museu de Arte Contemporânea, Museu de História Natural, Monumento do Índio e um aquário de água doce que se encontra em construção. Além disso, o parque dispõe de quadras esportivas, pista de caminhada, pátio para patins, skate e bicicleta. $\mathrm{O}$ parque ecológico do Sóter dispõe de quadras esportivas, pista de skate e patinação, pista de caminhada e corrida, bem como parque infantil.

O Parque Ayrton Senna dispõe de pistas de caminhada, campos de futebol, quadras esportivas, pista de atletismo, piscinas, academia ao ar livre e teatro de arena. $\mathrm{O}$ Parque Tarsila do Amaral, por sua vez, dispõe de quadras esportivas cobertas, campos de futebol, piscinas, e profissionais de educação física supervisionando os exercícios físicos. Por fim, o Parque Jaques da Luz, dispõe de campos de futebol, quadras poliesportivas, pista de caminhada, palco de apresentações, sala de arte, sala de dança, sala de informática.

A coleta de dados da pesquisa foi realizada entre os anos de 2010 e 2014 .

Quadro 1 - Parques esportivos de Campo Grande/MS

\begin{tabular}{c|c|c|c|c}
\hline Parques & Bairro & Região & Ano de fundação & Área \\
\hline Nações Indígenas & Santa Fé & Prosa & 1993 & 119 hectares \\
Ecológico do & Mata do Jacinto & Prosa & 2004 & 22 hectares \\
Sóter & & & & \\
Ayrton Senna & Aero Rancho & Anhanduizinho & 1994 & 32 hectares \\
Tarsila do Amaral & Nova Lima & Segredo & 2006 & 45 hectares \\
Jaques da Luz & Moreninhas & Bandeira & 1994 & 45 hectares \\
\hline
\end{tabular}

Fonte: Dados da pesquisa 
A técnica adotada foi a avaliação morfológica normativa (GAUTHIER; GILLILAND, 2006), caracterizada pela análise da formação física da cidade e seus componentes elementares - constituição do tecido urbano (edificações, ruas, quadras e lotes, parques, praças e monumentos), transformações ocorridas em decorrência dos fatores culturais, econômicos, sociais e políticos e a indicação de formas (normatizações) a partir das quais a cidade deveria ser planejada e construída (REGO; MENEGUETTI, 2011).

Utilizamos, ademais, a observação direta dos parques esportivos. Como instrumento adotamos um checklist de vistoria (estacionamento, passeio público, acesso, circulação horizontal, circulação vertical, sanitários e vestiários, mobiliários e espaços esportivos), idealizado pela Secretaria Municipal de Pessoa com Deficiência e Mobilidade Reduzida de São Paulo (SÃO PAULO, 2009). Além disso, foram observadas à largura dos corredores, sinalização de degraus, pisos, rampas, degraus e escadas, corrimãos, elevadores, portas, rebaixamento de calçadas para travessia de pedestres, estacionamento, sanitários, telefones públicos e bebedouros.

A escolha do checklist se deu por ser o único instrumento brasileiro que traduz de forma sintética as Normas Brasileiras para Acessibilidade, Edificação, Mobiliário, Espaços e Equipamentos Urbanos - NBR9050/2004, estabelecidas pela Associação Brasileira de Normas Técnicas - ABNT (ABNT, 2004).

Na classificação dos parques e seus elementos em acessíveis ou inacessíveis, recorremos às recomendações da NBR9050, que em seu item 1.3.1 expõe que:

Todos os espaços, edificações, mobiliário e equipamentos urbanos que vierem a ser projetados, construídos, montados ou implantados, bem como as reformas e ampliações de edificações e equipamentos urbanos, devem atender ao disposto nesta Norma para serem considerados acessíveis (ABNT, 2004, p. 1). 
O estudo atendeu às exigências da Resolução nº 196/96 do Conselho Nacional de Saúde e foi aprovado pelo Comitê de Ética em Pesquisa da Universidade Católica de Brasília, conforme o $\mathrm{n}^{\mathrm{o}} 262 / 2010$.

$\mathrm{Na}$ interpretação dos resultados, utilizamos a análise de frequência absoluta, indicando a quantidade de itens existentes em cada parque. Assim, os resultados foram organizados a partir dos seguintes itens: 1. Estacionamento; 2. Passeio Público; 3. Acesso; 4. Circulação horizontal; 5. Circulação vertical; 6. Sanitários e vestiários; 7. Mobiliários; 8. Espaços esportivos; classificando a quantidade acessível, os ausentes e os inadequados.

\section{Resultados e Discussões}

O primeiro item analisado foi estacionamentos reservados para veículos automotores que conduzam ou seja conduzidos por pessoas com deficiência física e os resultados indicaram que na maioria dos parques não há demarcação de vagas. Apenas o Parque das Nações Indígenas dispõe de dois estacionamentos em condições acessíveis, conforme resultados da Tabela 1.

Tabela 1 - Estacionamentos dos parques esportivos de Campo Grande/MS

\begin{tabular}{|c|c|c|c|c|c|}
\hline & \multicolumn{5}{|c|}{ Parques } \\
\hline & Jaques & Airton & Sóter & Tarsila & Nações \\
\hline Total de estacionamentos & 0 & 1 & 2 & 1 & 20 \\
\hline Estacionamentos acessíveis & 0 & 0 & 0 & 0 & 2 \\
\hline \multicolumn{6}{|l|}{ ITENS } \\
\hline \multicolumn{6}{|l|}{ Ausentes } \\
\hline \multicolumn{6}{|l|}{$\begin{array}{l}\text { Demarcação de faixa adicional para transferência e circulação de } \\
\text { passageiros }\end{array}$} \\
\hline Rebaixamento de calçada & & & & 1 & \\
\hline $\begin{array}{l}\text { Reserva de vagas em via pública à veículos que conduzam/sejam } \\
\text { conduzidos por pessoas com deficiência }\end{array}$ & & 1 & 2 & 1 & 16 \\
\hline Rotas acessíveis dos estacionamentos às entradas & & & 2 & & \\
\hline Sinalização tátil dos rebaixamentos de calçadas & & & 2 & & \\
\hline \multicolumn{6}{|l|}{ Inadequados } \\
\hline Compartilhamento da faixa adicional para circulação de pessoas & & & & & \\
\hline $\begin{array}{l}\text { em cadeira de rodas por duas vagas } \\
\text { Pintura da adicional em inadequada }\end{array}$ & & & & & $\begin{array}{l}2 \\
2\end{array}$ \\
\hline Superficie do piso irregular & & & 2 & & \\
\hline
\end{tabular}

A ausência de reserva de vagas preferenciais nos estacionamentos em parques esportivos, a exemplo do observado em Campo Grande, é incidente em outras 
localidades, como observado em outras pesquisas realizadas no setor hoteleiro de Camboriú/SC (SILVA, 2006) e em parques aquáticos de Irati/PR (BÁCIL; WATZLAWICK, 2007). Dados similares foram observados em âmbito internacional, conforme os resultados de uma pesquisa realizada nos ginásios de esportes portugueses, quando foi identificada a insuficiência da quantidade de vagas reservadas as pessoas com deficiência (ANDRADE, 2009).

Observa-se que as dificuldades de uso de equipamentos específicos de lazer por pessoas com deficiência física e visual se iniciam desde o acesso ao espaço. As pessoas com deficiência que dispõem de veículos automotores para conduzirem ou serem conduzidos se deparam com várias irregularidades, o que exige dos que optam por fazer uso desses bens culturais agirem por conta própria e criarem suas próprias alternativas a fim de superar as barreiras físicas existentes.

Não obstante, é o que foi observado no segundo item analisado, calçadas públicas, já que todos os parques demonstraram ausência de algum dos itens que contemplam os parâmetros da acessibilidade arquitetônica universal, conforme Tabela 2. Destacam-se a falta de rebaixamento de calçadas com a devida sinalização por piso tátil de alerta e a instalação inadequada de equipamentos de infraestrutura no percurso de circulação. Esta irregularidade é agravada pela não instalação de piso tátil de alerta na projeção dessas barreiras. 
Tabela 2 - Calçadas públicas dos parques esportivos de Campo Grande/MS

\begin{tabular}{|c|c|c|c|c|c|}
\hline & \multicolumn{5}{|c|}{ Parques } \\
\hline & Jaques & Airton & Sóter & Tarsila & Nações \\
\hline Total de passeios públicos & 2 & 4 & 4 & 1 & 2 \\
\hline Passeios públicos acessíveis & 0 & 0 & 0 & 0 & 0 \\
\hline \multicolumn{6}{|l|}{ ITENS } \\
\hline \multicolumn{6}{|l|}{ Ausentes } \\
\hline Sinalização tátil de alerta em rampas de acesso & & & 1 & & \\
\hline Sinalização tátil de alerta em rebaixamento de calçadas & 2 & 4 & 3 & 1 & 1 \\
\hline Sinalização tátil de alerta na projeção de barreiras fisicas & 2 & 1 & & & 2 \\
\hline \multicolumn{6}{|l|}{ Inadequados } \\
\hline Desníveis no piso & 2 & & & & \\
\hline Largura do vão livre inadequada & & & & & 1 \\
\hline Obstrução por barreira fisica de infraestrutura & 2 & 1 & & & 2 \\
\hline Obstrução por barreira física vegetativa & 2 & & 1 & & \\
\hline Superficie do piso irregular & & & 4 & & \\
\hline
\end{tabular}

Fonte: dados da pesquisa.

A inobservância da edificação de calçadas públicas pautadas no desenho universal também foi identificada no Rio de Janeiro, quando foi identificada a dificuldade das pessoas com deficiência visual em desviar dos orelhões. Estas barreiras se constituíram como não perceptíveis à varredura da bengala e de transpor o percurso da rua devido à ausência de sinalização sonora e temporização insuficiente para a travessia (DAVID; ANTUNES; GURGEL, 2009).

Algo semelhante ocorre com as pessoas com deficiência física, que se deparam com as dificuldades e riscos decorrentes de calçadas e ruas irregulares (HUNGER; SQUARCINI; PEREIRA, 2004). Outras dificuldades são as inadequações no tipo de piso e existência de buracos, ausência de rampas e rebaixamento de calçadas (COHEN, 2006).

As pessoas com deficiência física ou visual acabam com as possibilidades de deslocamento restringidas pela existência de barreiras físicas. Destacam-se a inadequação dos elementos de infraestrutura urbana, em virtude da ausência de adequação das calçadas públicas ao desenho universal, sendo-lhes assim usurpado o direito de ir e vir em suas atividades cotidianas, dentre elas, as de lazer.

Além de inibir o acesso aos equipamentos urbanos e de uso coletivo, a não promoção da acessibilidade arquitetônica em locais de deslocamento, como as calçadas, 
colocam em risco a integridade física e psicológica das pessoas com deficiência. As inadequações podem ainda provocar acidentes, como a virada de cadeiras de rodas e colisão de pessoas com deficiência visual.

De uma forma geral os passeios públicos analisados não estão preparados para lidar com as pessoas com deficiência física e visual, já que as limitações observadas em relação a esta população resultam da inadequação dos espaços urbanos. A não promoção da acessibilidade se configura em um tipo de violência física e psicológica que poderia ser evitada se os passeios públicos estivessem adequadamente instalados.

Para além do acesso, as barreiras no deslocamento e uso dos equipamentos para o lazer contemplativo ou prático não é diferente. Foram verificadas, em todos os parques, inadequações no portão de acesso, circulação horizontal e vertical, sanitários, mobiliários e espaços esportivos.

Em relação ao terceiro item analisado, portão de acesso, dentre as inadequações, predominaram aquelas relacionadas à superfície, composta na maioria por lama asfáltica, conforme tabela 3. As inadequações na superfície são promotoras de desconforto por causar trepidação, embora não promova barreiras às pessoas com deficiência visual, e não impeçam a locomoção de pessoas em cadeiras de rodas. 
Tabela 3 - Portões de acesso aos parques esportivos de Campo Grande/MS

\begin{tabular}{|c|c|c|c|c|c|}
\hline & \multicolumn{5}{|c|}{ Parques } \\
\hline & Jaques & Airton & Sóter & Tarsila & Nações \\
\hline Total de acessos & 3 & 4 & 3 & 1 & 6 \\
\hline Acessos acessíveis & 0 & 0 & 0 & 0 & 0 \\
\hline ITENS & & & & & \\
\hline Ausentes & & & & & \\
\hline Sinalização com piso tátil de alerta & & & & 1 & \\
\hline $\begin{array}{l}\text { Sinalização de entrada acessível em portões de entrada } \\
\text { acessíveis }\end{array}$ & 1 & & & & 3 \\
\hline $\begin{array}{l}\text { Sinalização indicativa das entradas que dispõem de portões } \\
\text { acessíveis }\end{array}$ & 2 & & & & 3 \\
\hline Inadequados & & & & & \\
\hline Barreira física no vão de passagem & 1 & 1 & & & \\
\hline Desnivel em forma de degrau & & & & 1 & 1 \\
\hline $\begin{array}{l}\text { Distância dos portões acessíveis em relação aos não } \\
\text { acessíveis superior a } 50 \mathrm{~m}\end{array}$ & 1 & & & & 3 \\
\hline Inclinação de rampa de acesso acima do permitido & & & & & 1 \\
\hline Largura livre do vão de passagem & 1 & 2 & & & \\
\hline Portão constantemente fechado & & 1 & & & \\
\hline Rampa irregular & & & & & 1 \\
\hline Sinalização tátil de alerta em rampas de acesso & & & & & 2 \\
\hline Superficie do piso irregular & 1 & 3 & 3 & & 1 \\
\hline
\end{tabular}

Em dois parques a caracterização de quatro entradas como inacessíveis decorreu da ausência de sinalizações, bem como da falta de indicação, por meio do símbolo internacional de acessibilidade. Somou-se a isso a distância entre os portões acessíveis e os portões não acessíveis, que deveria ser no máximo de 50 metros.

No quarto item, circulação horizontal, apenas quatro vias se encontravam acessíveis no momento de coleta de dados, no entanto, não são suficientes para promover o acesso aos parques esportivos. A maioria das vias de circulação horizontam se encontram irregulares por sua superfície ser em lama asfáltica, conforme Tabela 4, o que provoca desconforto no uso de cadeiras de rodas. 
Tabela 4 - Vias de circulação horizontal dos parques esportivos de Campo Grande/MS

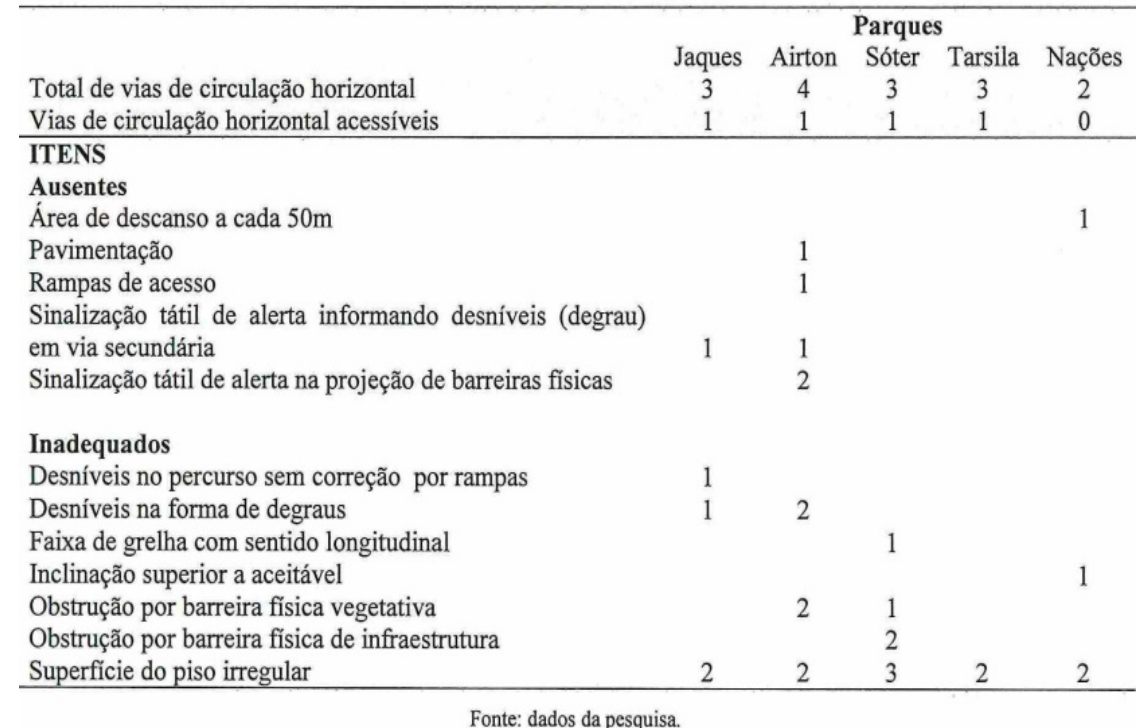

No quinto item, circulação vertical, foi possível verificar que as rampas e escadas são inacessíveis em todos os parques esportivos de Campo Grande, por não disporem dos itens de segurança (corrimãos em ambos os lados, piso tátil de alerta no início e término dos trajetos). As escadas se configuram como barreiras arquitetônicas que dificultam o acesso das pessoas com deficiência física e visual aos palcos em três equipamentos esportivos analisados.

Tabela 5 - Elementos de circulação vertical dos parques esportivos de Campo Grande/MS

\begin{tabular}{|c|c|c|c|c|c|}
\hline \multirow[b]{2}{*}{ RAMPAS } & \multicolumn{5}{|c|}{ Parques } \\
\hline & Jaques & Airton & Sóter & Tarsila & Nações \\
\hline Total de rampas & 1 & 1 & 1 & 1 & 0 \\
\hline Rampas acessíveis & 0 & 0 & 0 & 0 & 0 \\
\hline \multicolumn{6}{|l|}{ ITENS } \\
\hline \multicolumn{6}{|l|}{ Ausentes } \\
\hline Corrimãos em ambos os lados & 1 & 1 & 1 & 1 & \\
\hline Piso tátil de alerta no início e término & 1 & 1 & 1 & 1 & \\
\hline \multicolumn{6}{|l|}{ Inadequados } \\
\hline Corrimãos apenas em um lado & & 1 & 1 & 1 & \\
\hline Superfície do piso instável & & 1 & & & \\
\hline \multicolumn{6}{|l|}{ ESCADAS } \\
\hline Total de escadas & 1 & 1 & 1 & 1 & 3 \\
\hline Escadas acessíveis & 0 & 0 & 0 & 0 & 0 \\
\hline \multicolumn{6}{|l|}{ ITENS } \\
\hline \multicolumn{6}{|l|}{ Ausentes } \\
\hline Corrimãos em ambos os lados & 1 & 1 & 1 & 1 & 3 \\
\hline Faixa de cor contrastante nos degraus & 1 & 1 & 1 & 1 & 3 \\
\hline $\begin{array}{l}\text { Sinalizações táteis de advertência no início e final dos } \\
\text { degraus }\end{array}$ & 1 & 1 & 1 & 1 & 3 \\
\hline \multicolumn{6}{|l|}{ Inadequados } \\
\hline Distanciamento do primeiro e último degrau da circulação & & 1 & & & \\
\hline Largura & 1 & & & & \\
\hline Superfície do piso instável & & 1 & & & \\
\hline
\end{tabular}

Fonte: dados da pesquisa. 
Além de indisponíveis em alguns locais, nota-se que as rampas de acesso se encontram inadequadas, os responsáveis por seu planejamento, implantação e fiscalização não se atentaram às suas finalidades. As rampas são implantadas para promover o deslocamento vertical de pessoas em cadeira de rodas e com mobilidade reduzida, para que todas as pessoas possam exercer seu direito de ir e vir com autonomia, segurança e conforto. Assim, é indispensável que as rampas sejam equipadas com todos os itens preconizados pela legislação.

Os Banheiros e vestiários se configuram como o sexto item analisado no presente artigo. Em relação aos banheiros, todos os parques investigados apresentaram adequação às normas. No entanto, foram reportadas a ausência de sinalizações (informativas e sonoras de emergência) e as inadequações na altura de instalação (bacia sanitária, papeleira e barras de apoio) como os principais problemas. Além disso, os vestiários adaptados são inexistentes na maioria dos parques. 
Tabela 6 - Banheiros e vestiários dos parques esportivos de Campo Grande/MS

\begin{tabular}{|c|c|c|c|c|c|}
\hline \multirow[b]{3}{*}{ Total de hanheiros adantados } & \multicolumn{5}{|c|}{ Parques } \\
\hline & Jaques & Airton & Sóter & Tarsila & Nações \\
\hline & 2 & 2 & 2 & 2 & 6 \\
\hline Banheiros adaptados acessíveis & & & & & \\
\hline \multirow{2}{*}{\multicolumn{6}{|c|}{ SINALIZAÇÃO }} \\
\hline \multicolumn{4}{|l|}{ ITENS } & & \\
\hline \multicolumn{6}{|l|}{ Ausentes } \\
\hline Sinalização informativa de banheiros acessíveis & & & 2 & 2 & 6 \\
\hline Sinalização sonora de emergência & 2 & 2 & 2 & 2 & 6 \\
\hline \multicolumn{6}{|l|}{ Inadequados } \\
\hline Sinalização informativa de banheiros acessíveis fora das & & & & & \\
\hline normas & 2 & 2 & & & \\
\hline \multicolumn{6}{|l|}{ SANITÁRIOS E LAVATÓRIOS } \\
\hline \multirow{2}{*}{\multicolumn{6}{|c|}{$\begin{array}{l}\text { ITENS } \\
\text { Ausentes }\end{array}$}} \\
\hline & & & & & \\
\hline Boxes adaptados & 2 & & & & 6 \\
\hline Barras de apoio nos lavatórios & 2 & 2 & & & 6 \\
\hline Lavatórios correspondentes as bacias sanitárias & 2 & 2 & & & 6 \\
\hline Módulo de referência & & 2 & & & 6 \\
\hline Sóculo na bacia sanitária & & & 2 & & 6 \\
\hline \multicolumn{6}{|l|}{ Inadequados } \\
\hline Altura das barras de apoio & & & 2 & & 6 \\
\hline Altura da bacia sanitária & & & 2 & 2 & 6 \\
\hline Altura das papeleiras & 2 & 2 & 2 & & 6 \\
\hline Comprimento das barras de apoio & 2 & 2 & & & 6 \\
\hline Dimensão do banheiro & & & 2 & & 6 \\
\hline Eixo de descarga & & & & & 6 \\
\hline Espelhos & & 2 & & & 6 \\
\hline Espessura das barras de apoio & 2 & & 2 & & 6 \\
\hline Instalado em local isolado & 2 & & & & 6 \\
\hline Torneiras & & 2 & & & 6 \\
\hline VESTIÁRIO & 2 & 2 & 0 & 0 & 0 \\
\hline ITENS & 0 & 0 & 0 & 0 & 0 \\
\hline \multicolumn{6}{|l|}{ Ausentes } \\
\hline Bancos acessíveis às pessoas com deficiência & 2 & 2 & & & \\
\hline Cabinas individuais adaptadas para troca de roupas & 2 & 2 & & & \\
\hline
\end{tabular}

Além de essencial para a realização de necessidades fisiológicas, a existência de sanitários equipados com lavatórios e vestiários é de grande relevância para a preparação esportiva.

A inadequação às condições das pessoas com deficiência física e visual também foi evidenciada nos mobiliários, sétimo item analisado. Pode-se destacar a ausência de telefone público e de bebedouros ou inadequação de vários itens, como mesas fixas de concreto e assentos. 
Tabela 7 - Mobiliários dos parques esportivos de Campo Grande/MS

\begin{tabular}{|c|c|c|c|c|c|}
\hline & \multicolumn{5}{|c|}{ Parques } \\
\hline & Jaques & Airton & Sóter & Tarsila & Nações \\
\hline \multicolumn{6}{|l|}{ TELEFONE PÚBLICO } \\
\hline Total de telefones público & 1 & 0 & 0 & 0 & 3 \\
\hline Telefones público acessiveis & 0 & 0 & 0 & 0 & 0 \\
\hline \multicolumn{6}{|l|}{ ITENS } \\
\hline \multicolumn{6}{|l|}{ Ausentes } \\
\hline Amplificador de sinal & 1 & & & & 3 \\
\hline Área de aproximação & 1 & & & & 3 \\
\hline Piso tátil de alerta indicando situação de risco & 1 & & & & 3 \\
\hline \multicolumn{6}{|l|}{ Inadequados } \\
\hline Altura do anteparo superior de proteção inferior a exigida & 1 & & & & 3 \\
\hline Altura do operacional superior ao permitido & 1 & & & & 3 \\
\hline \multicolumn{6}{|l|}{ BEBEDOURO } \\
\hline Total de bebedouros & 1 & 1 & & & \\
\hline Bebedouros acessíveis & 0 & 0 & & & \\
\hline \multicolumn{6}{|l|}{ ITENS } \\
\hline \multicolumn{6}{|l|}{ Ausentes } \\
\hline Módulo de referência para aproximação frontal & 1 & 1 & & & \\
\hline \multicolumn{6}{|l|}{ Inadequados } \\
\hline Altura da bica d'água & 1 & & & & \\
\hline Localização dos controles do aparelho & 2 & & & & \\
\hline Utilização e o manuseio por meio de copo & 1 & & & & \\
\hline \multicolumn{6}{|l|}{ MESAS FIXAS EM CONCRETO } \\
\hline Total de mesas fixas & & & 10 & & \\
\hline Mesas fixas acessíveis & & & & & \\
\hline \multicolumn{6}{|l|}{ ITENS } \\
\hline \multicolumn{6}{|l|}{ Ausentes } \\
\hline Circulação e área de manobra & & & 10 & & \\
\hline Módulo de referência & & & 10 & & \\
\hline Rota acessível & & & 10 & & \\
\hline \multicolumn{6}{|l|}{ Inadequados } \\
\hline Altura livre inferior & & & 10 & & \\
\hline Altura superior do tampo da mesa & & & 10 & & \\
\hline \multicolumn{6}{|l|}{ BANCOS FIXOS } \\
\hline Total de bancos fixos & 11 & 5 & 49 & & 27 \\
\hline Bancos fixos acessíveis & 11 & 0 & 0 & & 0 \\
\hline \multicolumn{6}{|l|}{ ITENS } \\
\hline \multicolumn{6}{|l|}{ Ausentes } \\
\hline Módulo de referência & 11 & 4 & 27 & & 27 \\
\hline \multicolumn{6}{|l|}{ Inadequados } \\
\hline Desnivel em forma de degrau superior a $5 \mathrm{~cm}$ & 2 & 5 & & & 27 \\
\hline Interferência a faixa livre de circulação & & & 22 & & \\
\hline Superfície do piso irregular & 11 & & 27 & & 27 \\
\hline
\end{tabular}

Para finalizar, os espaços esportivos, se configuram como o oitavo e último item analisado. $\mathrm{O}$ acesso das diversas modalidades esportivas adaptadas metodológica e instrumentalmente não foi efetivado, uma vez que os parques esportivos não se encontravam adequados às normas. Apenas dois parques (Jaques da Luz e Ayrton Senna) apresentaram complexos poliesportivos acessíveis, e vários espaços não apresentam acessibilidade arquitetônica, com destaque para as 17 quadras poliesportivas descobertas, nove piscinas, duas pistas de skates e duas canchas de bocha. 
Tabela 8 - Quadras esportivas dos parques esportivos de Campo Grande/MS

\begin{tabular}{|c|c|c|c|c|c|}
\hline \multirow{4}{*}{$\begin{array}{l}\text { Total de quadras poliesportivas descobertas } \\
\text { Quadras poliesportivas acessíveis }\end{array}$} & \multicolumn{5}{|c|}{ Parques } \\
\hline & Jaques & Airton & Sóter & Tarsila & Nações \\
\hline & 2 & 10 & 2 & 0 & 3 \\
\hline & 0 & 0 & 0 & 0 & 0 \\
\hline \multicolumn{6}{|l|}{ ITENS } \\
\hline \multicolumn{6}{|l|}{ Ausentes } \\
\hline Corrimãos em ambos os lados da escada na via de acesso & & 10 & & & 3 \\
\hline $\begin{array}{l}\text { Corrimãos em ambos os lados da escada na entrada da } \\
\text { quadra }\end{array}$ & & & & & 2 \\
\hline \multicolumn{5}{|l|}{ Degraus da escada de acesso com faixa de cor de } & 3 \\
\hline Degraus na entrada do espaço de jogo (quadra) & & & & & 2 \\
\hline \multicolumn{6}{|l|}{$\begin{array}{l}\text { Degraus da escada da via de acesso com faixa de cor de } \\
\text { contrastante }\end{array}$} \\
\hline $\begin{array}{l}\text { Plataforma elevatória para rompimento do desnivel na via } \\
\text { de acesso }\end{array}$ & & 10 & & & 3 \\
\hline Rota acessível & 2 & 10 & & & 3 \\
\hline \multicolumn{6}{|l|}{ Sinalizações táteis de advertência no início e final da } \\
\hline $\begin{array}{l}\text { Sinalizações táteis de advertência no início e final da } \\
\text { escada na via de acesso }\end{array}$ & & & & & 2 \\
\hline \multicolumn{6}{|l|}{ Inadequações } \\
\hline Barreira física em forma de degrau na entrada da quadra & & & & & 2 \\
\hline Instalação no centro de canteiros de grama & 2 & 10 & & & 3 \\
\hline Largura do portão de entrada ao espaço de jogo (quadra) & & - & 2 & & \\
\hline Obstrução do vão da escada da via de acesso por barreira & & & & & \\
\hline física vegetativa & & 6 & & & 3 \\
\hline Presença de grama e mato no espaço de jogo & & 10 & & & \\
\hline Superfície do piso da via de acesso irregular & 2 & 10 & & & 3 \\
\hline
\end{tabular}

Fonte: dados da pesquisa.

Observa-se que as quadras poliesportivas descobertas estão inacessíveis, seja por não disporem de rotas estruturadas com piso e mecanismos de superação de desníveis (Parques Ayrton Senna e Nações Indígenas) ou por estarem instaladas no centro de canteiros de gramas e a superfície da rota de acesso estarem em piso irregular (Parques Jaques da Luz, Ayrton Senna e Nações Indígenas). Em relação ao espaço de jogo, as irregularidades observadas foram na largura do portão de entrada das duas quadras poliesportivas do Parque Ecológico do Sóter.

O uso das quadras por pessoas com deficiências físicas e visuais não está adequado. Os espaços de jogo de dez quadras do Parque Ayrton Senna se encontravam invadidas por grama. Além disso, duas quadras do Parque das Nações Indígenas apresentaram irregularidades nos degraus de acesso. 
Por sua vez, as piscinas, se encontravam inacessíveis nos três parques que constam o equipamento esportivo. Os critérios não atendidos para itens relacionados à parte externa são: superfície do piso próxima às piscinas, banco de transferência e dispositivos de acesso à água. Enquanto que na parte interna os itens não atendidos são: barras de apoio nas bordas internas e corrimãos das escadas submersas em três alturas.

Tabela 9 - Piscinas dos parques esportivos de Campo Grande/MS

\begin{tabular}{|c|c|c|c|c|c|}
\hline & \multicolumn{5}{|c|}{ Parques } \\
\hline & Jaques & Airton & Sóter & Tarsila & Nações \\
\hline Total de piscinas & 3 & 3 & 0 & 3 & 0 \\
\hline Piscinas acessíveis & 0 & 0 & 0 & 0 & 0 \\
\hline \multicolumn{6}{|l|}{ ITENS } \\
\hline \multicolumn{6}{|l|}{ Ausentes } \\
\hline Barras de apoio nas bordas internas & 3 & 3 & & 3 & \\
\hline Banco de transferência & 3 & 3 & & 3 & \\
\hline Corrimãos das escadas submersas em três alturas & 3 & 3 & & 3 & \\
\hline \multicolumn{6}{|c|}{ Dispositivos de acesso de pessoas em cadeira de rodas à } \\
\hline \multicolumn{6}{|l|}{ Inadequados } \\
\hline Alturas dos corrimãos & 3 & 3 & & & \\
\hline Desnível no portão de acesso & & & & 3 & \\
\hline Largura do portão inferior ao exigido & & & & 3 & \\
\hline Superficie do piso próximo as piscinas (instáveis) & 3 & 3 & & & \\
\hline
\end{tabular}

Fonte: dados da pesquisa.

As pistas de skate também são inacessíveis, sobretudo pela ausência de elementos de segurança no desnível vencido por escada (Parque das Nações Indígenas), sinalização tátil de alerta em rampas de acesso e inadequação do piso na rota de acesso (Parque Ecológico do Sóter).

Tabela 10 - Pistas de skate dos parques esportivos de Campo Grande/MS

\begin{tabular}{|c|c|c|c|c|c|}
\hline \multirow{4}{*}{$\begin{array}{l}\text { Total de pistas de skate } \\
\text { Pista de skate acessíveis }\end{array}$} & \multicolumn{5}{|c|}{ Parques } \\
\hline & Jaques & Airton & Sóter & Tarsila & Nações \\
\hline & & & 1 & & 1 \\
\hline & & & 0 & & 0 \\
\hline \multicolumn{6}{|l|}{ ITENS } \\
\hline \multicolumn{6}{|l|}{ Ausentes } \\
\hline Rota acessível & & & & & 2 \\
\hline Corrimãos em ambos os lados da escada de acesso & & & & & 2 \\
\hline Degraus da escada com faixa de cor contrastante & & & & & 2 \\
\hline Obstrução por barreira física vegetativa na via de acesso & & & & & 2 \\
\hline Sinalizações táteis de advertência no início e final da & & & & & \\
\hline escada & & & & & 2 \\
\hline Sinalização tátil de alerta em rampas de acesso & & & 1 & & \\
\hline \multicolumn{6}{|l|}{ Inadequados } \\
\hline Superfície do piso & & & & & 1 \\
\hline
\end{tabular}


No que tange aos campos de futebol e voleibol em areia, o acesso de pessoas com deficiência também se encontra inacessível. Apesar da inexistência de exigências/normas que regem como estes locais devem se equipar para promover o acesso de pessoas com deficiência física e visual, pode-se afirmar que a inclusão não está sendo realizada, uma vez que esse equipamento esportivo não se encontra nas normas.

De modo geral, resultados semelhantes aos analisados em Campo Grande/MS também foram obtidos em outras pesquisas realizadas no Brasil em parques aquáticos Irati/PR (BÁCIL; WATZLAWICK, 2007), parques em Salvador/BA (RIBEIRO et al., 2007) e em Natal/RN (MELO et al., 2010). Em âmbito internacional existem resultados semelhantes nas piscinas cobertas em Oviedo, Asturias (BUSTO; TORRE, 2006), em ginásios poliesportivos em Sintra, Portugal (ANDRADE, 2009), em centros recreativos em Ontário, Canadá (ARBOUR-NICITOPOULOS; GINIS, 2011) e em campos de golfe em Murcia, Espanha (ZARCO-PÉREZ et al., 2012). Em todas essas cidades diversos aspectos da acessibilidade arquitetônica não estavam presentes.

Ademais, a inacessibilidade física tem sido um problema que atinge não apenas espaços voltados à promoção do lazer de interesse físico/esportivo, sendo observada também em equipamentos que fomentam outros conteúdos culturais, como os hotéis (PANOSSO, PANNO, 2010), as bibliotecas (BARRETO; COUTINHO, 2012) e os centros culturais (OLIVEIRA, 2006).

Os dados obtidos indicam que, embora todos os parques esportivos de Campo Grande/MS tenham sido construídos anteriormente às leis normalizadoras da acessibilidade do país (conforme estabelece o artigo 19, inciso $1^{\circ}$ do Decreto $\mathrm{n}^{0} 5.296$, de 2 de dezembro de 2004) (BRASIL, 2004), as adequações que deveriam ter ocorrido 
em um prazo máximo de trinta meses a partir da data de publicação do decreto não foram cumpridas. As exigências da NBR9050/2004 e do decreto supracitado, assim como da Lei de Política de Desenvolvimento e Plano Diretor do município - Lei n ${ }^{\circ} 94$, de 6 de outubro de 2006 (CAMPO GRANDE, 2006) e de Ordenamento do uso e da ocupação do solo - Lei n ${ }^{0}$ 186, de 12 de dezembro de 2011 (CAMPO GRANDE, 2011), não são atendidas. Assim, todos os parques esportivos se encontraram inacessíveis às pessoas com deficiência física e visual.

A partir de sua inserção na Constituição Federal Brasileira de 1988 foram necessários 12 anos para a elaboração de uma lei federal com as especificações e normatização da promoção da acessibilidade - Lei $\mathrm{n}^{0}$ 10.098, de 19 de dezembro de 2000 - e 16 anos para estipular um prazo para o seu cumprimento - Decreto $\mathrm{n}^{0} 5.296$, de 02 de dezembro de 2004 - expirado desde 2007. Além de tardia, a inclusão de pessoas com deficiência física e visual por meio da adequação dos equipamentos específicos de lazer às condições universais continua a ser negada.

No plano legal, institucional e formativo, ações importantes a respeito da acessibilidade arquitetônica são desenvolvidas no Brasil com objetivos voltados para sua normatização - normas técnicas (ABNT, 2004), Decreto $\mathrm{n}^{0} 5.296$, de 2 de dezembro de 2004 (BRASIL, 2004) -; administração - Ministério da Cidade e Secretaria de Estado dos Direitos da Pessoa com Deficiência em São Paulo, dentre outras - e conscientização da sociedade por meio de cartilhas e guias de informação - endereçadas a profissionais da engenharia, arquitetura e agronomia (SÃO PAULO, 2005), da administração pública (CEARÁ, 2009), do mercado imobiliário (SÃO JOSÉ DOS CAMPOS, s/d) e à população em geral (PORTO ALEGRE, 2007) sobre a importância de sua promoção. No entanto, no âmbito da efetivação de políticas públicas, notam-se 
tendências não animadoras, haja vista que, conforme indicam os dados obtidos nesta investigação, as mesmas não têm sido materializadas por intermédio da adequação dos espaços a lei.

Considerando a estrutura dos parques esportivos, com inadequações e ausências de elementos que atendam à acessibilidade arquitetônica, despreparados para receber adequadamente as pessoas com deficiência física ou visual, é possível que esses espaços não estejam usufruídos pela população em estudo. As inadequações figuram como barreiras físicas que dificultam o acesso ao parque, o deslocamento no seu interior e, consequentemente, o seu uso. Questões como essas nos levam a concordar com Lefebvre (2001) quando afirma que o conceito de urbanismo dos administradores públicos tende a negligenciar o fator humano da cidade.

O não atendimento dos parâmetros normativos de acessibilidade arquitetônica em Campo Grande/MS corrobora para que 22,94\% da população campo-grandense 16,56\% (130.334) com deficiência visual e 6,38\% (50.247) - com deficiência física (CAMPO GRANDE, 2012), tenham seu direito de ir e vir violado. Dessa forma, suas oportunidades de lazer são restringidas em decorrência da existência de barreiras físicas em suas diversas formas.

Isto porque ambientes que fogem aos preceitos arquitetônicos do paradigma do desenho universal para se pautarem nos princípios norteadores do "homem-padrão", além de não assegurarem o deslocamento e uso com autonomia, segurança e conforto, colocam a deficiência em evidência. $\mathrm{O}$ não atendimento as normas arquitetônicas corroboram para que os estereótipos sejam reforçados e suas possibilidades de ação diminuídas, visto que as características do ambiente influenciam a ação do sujeito sobre o meio. 
Inviabilizado o deslocamento pelo passeio, o acesso e a livre circulação sobre suas dependências com autonomia, segurança e conforto, os parques esportivos de Campo Grande/MS limitam e inibem as pessoas com deficiência física e visual de usufruí-los como espaço de lazer. De acordo com Santos (2012), os espaços se caracterizam pelo movimento humano sobre a paisagem, a ação social sobre formas geográficas, a sociedade encaixada na paisagem, a vida que anima as formas/objetos.

Se a relação com um dado espaço se encontra relacionada à identificação criada com ele, apropriando-o como lugar ou repelindo-o, a ausência de acessibilidade arquitetônica indica que os parques esportivos analisados não têm figurado como lugar de inclusão das pessoas com deficiência. Isto, porque as barreiras existentes restringem e até mesmo impedem que essa população usufrua do espaço.

Para que exista um sentimento de pertencimento ao lugar é necessário que todo e qualquer tipo de barreiras arquitetônicas sejam removidas (JOHNSTONE, 2003), assumimos que os parques esportivos analisados, equipamentos urbanos que deveriam figurar como lugar de inclusão, se configuram como espaço de exclusão das pessoas com deficiência física e visual.

A violação do direito civil de ir e vir, impedem as pessoas com deficiência de acesso e permanência aos espaços públicos, bem como de usufruir do lazer como direito social. Além disso, inibe o convívio e relacionamento social, visto que os riscos de acidentes, preconceitos e sentimento de não pertencimento são fatores que podem corroborar para que muitos sejam levados a viverem reclusos em suas casas.

Desse modo, a partir da análise dos dados é possível afirmar que os parques esportivos analisados são espaços de exclusão das pessoas com deficiência física e visual, que não proporciona nem a função de paisagem, com um olhar distante e de fora. 
A paisagem é tudo aquilo que nós conseguimos alcançar por meio da visão (SANTOS, 2012), e essa possibilidade é negada as pessoas com deficiência, pois formas adaptadas de leitura para pessoas com deficiência visual e percepção do ambiente por intermédio do tato (maquetes) ou da audição (dispositivos de áudio com narrativa do local) não se encontram disponíveis no local.

\section{Considerações Finais}

O presente artigo atingiu o objetivo de analisar os parques esportivos de Campo Grande/MS, a partir do momento que realizou a análise e aplicação do questionário de normas de acesso das pessoas com deficiência física e visual, a partir da discussão científica sobre paisagem, espaço e lugar. Dessa forma, é possível concluir, na forma de denúncia, que os parques esportivos se encontram inacessíveis e se configuram como espaço de exclusão e não como lugar de inclusão das pessoas com deficiência física e visual.

A análise dos dados no presente artigo serve como um diagnóstico para o poder público municipal, estadual e federal planejar e reavaliar os parques esportivos como lugar de pertencimento, com o objetivo de promover o acesso e uso adequado das pessoas com deficiência física e visual. Construir ou não adaptar os equipamentos esportivos para todas as pessoas com deficiência física e visual é negar o direito ao esporte e ao lazer, bem como o direito de ir e vir.

A violação do direito de acesso aos parques esportivos e o não cumprimento da legislação foram recorrentes na cidade de Campo Grande, desde a chegada aos estacionamentos, passeio público e acesso de uma forma geral nos equipamentos 
esportivos, até a mobilidade e uso no que diz respeito a circulação horizontal, circulação vertical, sanitário e vestiários, mobiliários, e espaços esportivos.

Por fim, os resultados dessa pesquisa são de grande relevância para a área de esporte e lazer no Brasil, a partir do momento que contribui para a compreensão sobre o acesso de todas as pessoas, de forma que o equipamento esportivo se configure como lugar de inclusão. Além disso, instiga novas pesquisas relacionadas as barreiras arquitetônicas que violam o direito de acesso ao lazer de uma forma universal.

\section{REFERÊNCIAS}

ABNT (Associação Brasileira de Normas Técnicas). NBR9050: Acessibilidade a edificações, mobiliário, espaços e equipamentos urbanos. Rio de Janeiro, 2004.

ANDRADE, C. S. A qualidade da acessibilidade nas instalações desportivas (ginásio). A qualidade da acessibilidade, para pessoas com mobilidade condicionada, em Ginásio/Salas de Exercícios, no Município de Sintra. 2009. 147 f. Dissertação (Mestrado) - Programa de Gestão do Desporto, UTL, Lisboa, 2009.

ARBOUR-NICITOPOULOS, K.; GINIS, K. M. Universal accessibility of "accessible" fitness and recreational facilities for persons with mobility disabilities. Adapted Physical Activity Quarterly, Champaign, v. 28, n. 1, p. 1-15, 2011.

BÁCIL, M. K.; WATZLAWICK, L. F. Análise da acessibilidade de pessoas com mobilidade reduzida no Parque Aquático, Irati-PR. Revista Eletrônica Lato Sensu, Distrito Federal, v. 2, n. 1, p. 1-25, 2007.

BARRETO, T. L. M.; COUTINHO, I. J. Avaliação de acessibilidade da biblioteca pública do estado da Bahia: discussões e reflexões. Revista Baiana de Terapia Ocupacional, Salvador, v. 1, n. 1, p. 57-65, 2012.

BRASIL. Decreto n. 5.296 de 2 de dezembro de 2004. Diário Oficial da República Federativa do Brasil, Brasília, 02 dez. 2004, p. 1-3.

BUSTO, A. L.; TORRE, A. A. La accesibilidad arquitectónica para personas com discapacidades sensoriales em los espacios desportivos de Asturias. Revista Lecturas, Educación Física y Deportes, Buenos Aires, v. 11, n. 103, p. 1-10, 2006.

CAMPO GRANDE. Lei complementar $\mathrm{n}^{0}$ 94, de 6 de outubro de 2006. Diário Oficial de Campo Grande, Campo Grande, 06 out. 2006, p.1-21

Lei complementar $\mathrm{n}^{0} 186$, de 12 de dezembro de 2011. Diário Oficial de Campo Grande, Campo Grande, 12 dez. 2011, p.1-41. 
CAMPO GRANDE. Perfil socioeconômico de Campo Grande. Campo Grande: PLANURB, 2012.

CEARÁ (Estado). Guia de acessibilidade: espaço público e edificação. Fortaleza: SEINFRA-CE, 2009.

COHEN, R. Cidade, corpo e deficiência: percursos e discursos possíveis na experiência urbana. 2006. 228 f. Tese (Doutorado) - Curso de Psicossociologia de Comunidades e Ecologia Social, UFRJ, Rio de Janeiro, 2006.

DAVID, J. S.; ANTUNES, X. M.; GURGEL, V. T. Cidade acessível: igualdade de direitos e particularidades da pessoa com deficiência visual. Fractal, Revista de Psicologia, Rio de Janeiro, v. 21, n. 5, p. 80-94, 2009

GAUTHIER, P.; GILLILAND, J. Mapping urban morphology: a classification scheme for interpreting contributions to the study of urban form. Urban Morphology, Madrid, v. 10, n. 1, p. 41-50, jan./abr. 2006.

GEHL, J. Cidades para pessoas. São Paulo: Perspectiva, 2013.

HUNGER, D.; SQUARCINI, C. F. R.; PEREIRA, J. M. A pessoa portadora de deficiência física e o lazer. Revista Brasileira de Ciências Esporte, Florianópolis, v. 25, n. 3, p. 85-100, 2004.

JACOBS, J. Morte e vida de grandes cidades. São Paulo: Editora WMF, 2000.

JOHNSTONE, D. Explorando os limites da inclusão: jovens deficientes e o seu sentido de lugar. In: RODRIGUES, D. Perspectivas sobre a inclusão: da educação a sociedade. Portugal: Porto editora, 2003. p. 197-208.

LEFEBVRE, H. O direito à cidade. São Paulo: Centauro, 2001.

LERNER, J. Prólogo à edição brasileira. In: GEHL, J. Cidades para pessoas. São Paulo: Perspectivas, 2013. p. XII.

MARCONI, M. A.; LAKATOS, E. M. Técnicas de pesquisa: planejamento e execução de pesquisas, amostragens e técnicas de pesquisas. 5. ed. São Paulo: Atlas, 2002.

MELO, F. R. L. V. et al. Estudo da acessibilidade em ambientes de lazer na cidade do Natal/RN. Licere, Belo Horizonte, v. 13, n. 2, p. 1-19, 2010.

OLIVEIRA, A. S. D. A. Acessibilidade Espacial em Centro Cultural: estudo de casos. 2006. 213 f. Dissertação (Mestrado) - Programa de Pós-graduação em Arquitetura e Urbanismo, UFSC, Florianópolis, 2006.

OLIVEIRA, S. L. Tratado de metodologia científica. 2. ed. São Paulo: Pioneira, 2002.

PANOSSO, A.; PANNO, G. Turismo e acessibilidade na cidade de São Paulo: da teoria à prática. Revista Itinerarium, Rio de Janeiro, v. 3, n. 1, p. 1-19, 2010. 
PORTO ALEGRE (Município). Porto Alegre acessível para todos. Prefeitura Municipal de Porto Alegre, Rio Grande do Sul, 2007.

REGO, R. L.; MENEGUETTI, K. S. A respeito de morfologia urbana. Tópicos básicos para estudos da forma da cidade. Acta Scientiarum Technology, Maringá, v. 33, n. 2, p. 123-127, 2011.

RIBEIRO, N. M. et al. Análise do ambiente de lazer para portadores de deficiência com alteração na locomoção, na cidade de Salvador. Diálogos possíveis, Salvador, v. 1, n. 1, p. 233-242, 2007.

SANTOS, M. A natureza do espaço. 4. ed. São Paulo: Editora da Universidade de São Paulo, 2009a.

Metamorfoses do espaço habitado: Fundamentos teóricos e metodológicos da geografia. 6. ed. São Paulo: Editora da Universidade de São Paulo, 2012.

. O lugar: encontrando o futuro. Rua Revista de Arquitetura, Salvador, v. 6, n. 4, p. 34-39, 1997.

Pensando o espaço do homem. 5. ed. São Paulo: Editora da Universidade de São Paulo, 2009b.

SÃO JOSÉ DOS CAMPOS (Município). Manual de acessibilidade para espaços internos: acessibilidade - qualidade de vida para todos. São José dos Campos: Prefeitura Municipal de São José dos Campos, s/d.

SÃO PAULO (Município). Acessibilidade: mobilidade acessível na cidade de São Paulo. São Paulo: Secretaria Especial da Pessoa com Deficiência e Mobilidade Reduzida/Prefeitura Municipal de São Paulo, 2005.

Roteiro básico para vistoria (critérios de avaliação de acessibilidade em edificações e projetos). Secretaria Municipal de Pessoa com Deficiência e Mobilidade Reduzida de São Paulo, 2009.

SILVA, Y. F. A estrutura hoteleira de Balneário Camboriú para turistas portadores de necessidades especiais. Turismo - Visão e Ação, Itajaí, v. 8, n. 1, p. 9-29, 2006.

TSCHOKE, A.; TARDIVO, T. G.; RECHIA, S. Como a escola se tornou também espaço de lazer da comunidade: os programas inseridos a escola Maria Marly Piovezan. Pensar a prática, Goiânia, v. 14, n. 1, p. 1-11, 2011.

TUAN, Y. F. Espaço e lugar: a perspectiva da experiência. São Paulo: Difel, 1983.

ZARCO-PÉREZ, P. et al. Análisis de la accessibilidad em los campos de golf de la región de Murcia. Cultura, Ciencia y Deporte, n. 8, v. 7, p. 89-94, 2012. 


\section{Endereço dos Autores:}

Junior Vagner Pereira da Silva

Rua Hélio Castro Maia, 714 - Jardim Paulista

Campo Grande - MS - 79.050-020

Endereço Eletrônico: jr_lazer@yahoo.com.br

Dirceu Santos Silva

Avenida Costa e Silva s/n

Cidade Universitária - Pioneiros

Campo Grande - MS - 79070-900

Endereço Eletrônico: dirceu_09@yahoo.com.br

Tânia Mara Vieira Sampaio

Instituto Federal de Educação, Ciência e Tecnologia de Goiás

Campus Luziânia. Rua São Bartolomeu - Vila Esperança

Luziânia - GO - 72.811-580

Endereço Eletrônico: taniamara_sampaio@hotmail.com 